\title{
Control of Inclusion Size and Toughness by Reactivity of Multiblock Copolymer in Epoxy Composites
}

\author{
Ren He, Xiaoli Zhan, Qinghua Zhang, Guangfa Zhang and Fengqiu Chen \\ College of Chemical and Biological Engineering, Zhejiang University, Hangzhou 310027, China \\ Correspondence to: Qinghua Zhang (E-mail: qhzhang@zju.edu.cn)
}

\begin{abstract}
:
In this paper, the strategy to achieve high fracture toughness and impact strength of epoxy blends by introducing a new family of reactive block copolymer (RBCP), poly[styrene-alt-(maleic anhydride)]block-polystyrene-block-poly(n-butyl acrylate)-block-polystyrene, with different reactivity is reported. Inclusions size of RBCP in cured blends was controlled from nanometer to micrometer by simply adjusting the fraction of reactive block in RBCP. The systematical study on the structure-property relationship revealed that the thermal and mechanical properties of modified blends strongly depend on inclusion size. The results suggested that blends containing nano inclusions of RBCP were more sensitive to test rates. And blends containing sub-micron inclusions showed substantially increased toughness in SENB measurements and IZOD impact tests without loss in $\mathrm{T}_{\mathrm{g}}$. The findings of this work provide an insight on developing toughened epoxy thermosets utilized for both high and low fracture rates via innovative reactive blending.
\end{abstract}

KEYWORDS: Epoxy, Block Copolymer, Toughening

\section{Introduction}

Epoxy resin is widely used in the fields of electron, machine, architecture, and so on for its outstanding mechanical, adhesive, and insulating properties. Since the brittleness is one of its major drawbacks, toughening of epoxy thermosets has been adequately developed in past few decades.[1-6] One of the most common and successful strategies is to incorporate a second phase such as rubbers, thermoplastic particles, or mineral fillers into epoxy matrices. [7-14] Among these studies, it has been demonstrated that mechanical toughness could be significantly improved by using diblock and triblock copolymers.[15-21] The incorporation of such block copolymers (BCPs) self-assemble and form various nanostructures in epoxy matrix.[22-24] Compared to traditional micro fillers, these nano-sized inclusions confer unique features to epoxy blends.[25, 26] One of these features relates to the interfacial area, where the distance between inclusions is comparable to the size of interfacial region.[27] This feature promotes interfacial stress transfer leading to significantly increased toughness of epoxy blends.

A strategy to obtain nano-sized inclusions is to facilitate interfacial effect by forming covalent links between the matrix and inclusion based on the chemical miscible concept. In this fashion, reactive groups are incorporated into initially miscible or immiscible block copolymers to promote covalent linkages binding two phases in blends.[28, 29] Epoxy groups are frequently introduced to BCPs to react with the amine end groups of hardeners.[30-32] And Nanostructured thermosets were obtained by introducing reactive block copolymer containing glycidyl methacrylate into epoxy blends.[31] By epoxidizing the residual double bond in polystyrene-blockpolybutadiene-block-polystyrene (SBS), domain size of epoxidized SBS in epoxy matrix was significantly reduced compare to SBS.[33-35] In general, BCPs containing reactive groups were 
estimated to be more effective in epoxy modification with better control of morphology compared to nonreactive BCPs.[30] Chemical bonding between BCPs and epoxy matrix can result in better toughening effects.[36, 37] However, the influence of reactivity of reactive $\mathrm{BCP}$ on the morphologies and mechanical performance of blends was not fully investigated.

The reactivity between copolymer containing maleic anhydride and epoxy blend was reported.[38] Reactive block copolymer, polystyrene-block-polybutadiene-block-poly[(methyl methacrylate)-stat(methacrylic acid)] SB(MA), modified epoxy blends were found to have almost no increase in fracture toughness compared to neat epoxy.[39] However, it would be more efficient in toughening if the sparse distributed reactive groups are concentrated in reactive block copolymers. We wonder if tetrablock copolymer, consisting of maleic-anhydride alternating structure which is epoxy-reactive and hard-softhard traditional elastomeric copolymer block sequence which is epoxy-immiscible, is efficient for toughness modification for thermosets. In our prior works, poly[styrene-alt-(maleic anhydride)]-blockpolystyrene-block-poly(n-butyl acrylate)-block-polystyrene tetrablock copolymers (SMA-PSt-PnBA-PSt) containing SMA as reactive block were prepared.[40] Taking advantage of recently developed RAFT polymerization, the reactivity of block copolymer can be tailored in a wide composition window.

In this work, DGEBA/DDM epoxy thermosets was modified by $10 \mathrm{wt} \%$ of RBCP SMA-PSt-PnBAPSt in different reactivity (molecular structure shown in Scheme 1). This paper would like to fully reveal the effect of maleic anhydride as reactive groups in copolymers on the nanostructure and mechanical performance of thermosets. The morphologies of blends were verified by TEM and FESEM observations. Thermal properties were investigated using dynamical mechanical thermal analysis by DMA. Toughness were evaluated by fracture toughness measurements and notched IZOD impact tests. The main emphasis of this research lies in reactivity of block copolymer on the improvement of miscibility, structural, and mechanical performance in modifying epoxy thermosets.

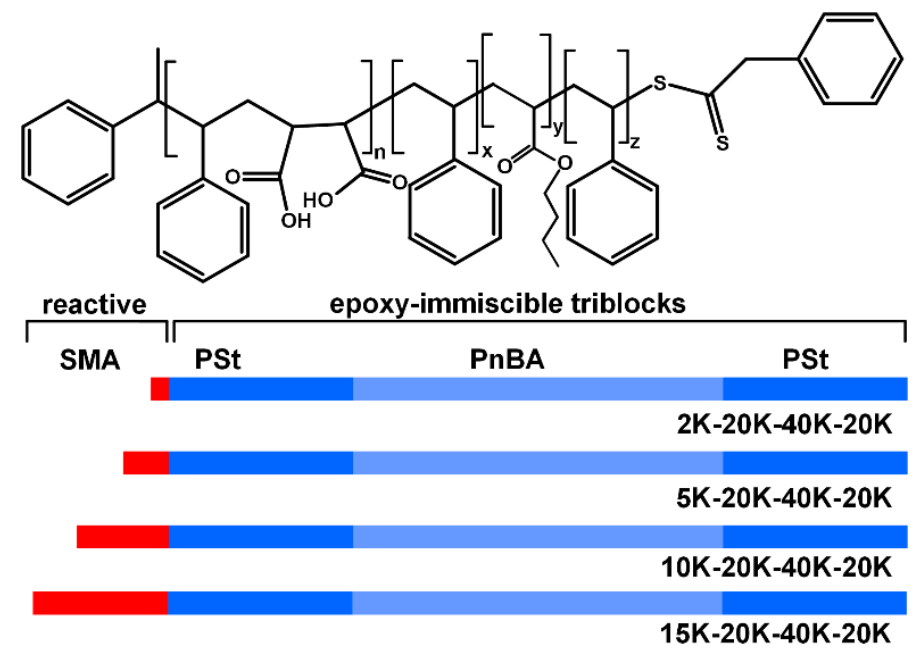

Scheme 1. Molecular structures of SMA-PSt-PnBA-PSt RBCP used in this study.

\section{Experimental}

\subsection{Materials}


A series of RBCP poly[styrene-alt-(maleic anhy-dride)]-block-polystyrene-block-poly(n-butyl acrylate)block-polystyrene (CABA type) were synthesized via RAFT miniemulsion polymerization mediated by amphiphilic macroRAFT agent. The synthesis method and process was descripted in literature.[40] The chemical structures of the tetrablock copolymers were presented in Table 1 . The tetrablock copolymer had SMA weight fractions $\left(w_{S M A}\right)$ ranging from $2.15 \mathrm{wt} \%$ to $15.93 \mathrm{wt} \%$. The maleic anhydride was partially hydrolysed during emulsion polymerization. The epoxy resin used in this study was diglycidyl ether of bisphenol A (DGEBA) (E51, Shanghai Resin Production, epoxy value 0.51 mol/100 g). 4, 4'diamino diphenyl methane (DDM, Aldrich) was used as hardener. Amino hydrogen to epoxy stoichiometric ratio of one was selected for all the systems. Tetrahydrofuran (THF, 99.9\%, Aldrich) was used as cosolvent to obtain homogeneous mixtures of high molecular weight BCP and DGEBA.

Table 1. Characteristics of SMA-PSt-PnBA-PSt RBCP used in this study.

\begin{tabular}{|c|c|c|c|c|c|}
\hline $\mathrm{RBCP}$ & Structure & $\mathrm{M}_{\mathrm{n}, \mathrm{BCP}}\left(\mathrm{g} \mathrm{mol}^{-1}\right)^{\mathrm{a}}$ & $\mathrm{PDI}_{\mathrm{BCP}}{ }^{\mathrm{a}}$ & $\mathrm{M}_{\mathrm{n}, \mathrm{SMA}}\left(\mathrm{g} \mathrm{mol}^{-1}\right)^{\mathrm{a}}$ & $\mathrm{w}_{\mathrm{SMA}}(\mathrm{wt} \%)^{\mathrm{b}}$ \\
\hline $\mathrm{R} 2 \mathrm{BCP}$ & $\mathrm{SMA}_{2 \mathrm{~K}}-\mathrm{PSt}_{20 \mathrm{~K}}-\mathrm{PnBA}_{40 \mathrm{~K}}-\mathrm{PSt}_{20 \mathrm{~K}}$ & 81,453 & 2.57 & 1,752 & 2.15 \\
\hline $\mathrm{R} 5 \mathrm{BCP}$ & $\mathrm{SMA}_{5 \mathrm{~K}}-\mathrm{PSt}_{20 \mathrm{~K}}-\mathrm{PnBA}_{40 \mathrm{~K}}-\mathrm{PSt}_{20 \mathrm{~K}}$ & 91,842 & 3.06 & 5,068 & 5.52 \\
\hline $\mathrm{R} 10 \mathrm{BCP}$ & $\mathrm{SMA}_{10 \mathrm{~K}}-\mathrm{PSt}_{20 \mathrm{~K}}-\mathrm{PnBA}_{40 \mathrm{~K}}-\mathrm{PSt}_{20 \mathrm{~K}}$ & 94,285 & 3.26 & 10,576 & 11.22 \\
\hline $\mathrm{R} 15 \mathrm{BCP}$ & $\mathrm{SMA}_{15 \mathrm{~K}}-\mathrm{PSt}_{20 \mathrm{~K}}-\mathrm{PnBA}_{40 \mathrm{~K}}-\mathrm{PSt}_{20 \mathrm{~K}}$ & 98,797 & 3.72 & 15,737 & 15.93 \\
\hline
\end{tabular}

${ }^{a}$ Molecular weights and PDIs of the SMA-PSt-PnBA-PSt tetrablock copolymers were measured by GPC (Waters 1525 Binary HPLC Pump, Waters 717 Autosampler, Waters 2414 Refractive Index Detector, Waters 2487 Dual $\lambda$ Absorbance Detector for UV 311 signals). The synthesized copolymer samples were dried in an oven at $100^{\circ} \mathrm{C}$ for $3 \mathrm{~h}$ and then dissolved in tetrahydrofuran (THF). The eluent was THF with a flow rate of $1.0 \mathrm{~mL} / \mathrm{min}$ and the testing temperature was $35^{\circ} \mathrm{C}$. The molecular weights and PDIs were derived from a calibration curve based on narrow polystyrene standards with molecular weight from 1,200 to $3,940,000 \mathrm{~g} / \mathrm{mol}$. Data was accumulative after chain extension. ${ }^{\mathrm{b}}$ Weight Percentage was calculated using data obtained from GPC measurements.

\subsection{Blending and curing of reactive block copolymer modified thermosets}

Due to the high molecular weight of RBCPs, THF was employed as cosolvent to facilitate homogeneous mixing of epoxy and RBCP at room temperature. Once homogeneity was achieved, the mixture was heated to $90{ }^{\circ} \mathrm{C}$ for complete removal of the solvent. Then a stoichiometric amount of hardener DDM was added to the mixture, magnetic stirred, until the hardener was completely dissolved. Uniform and bubblefree plaques were obtained by pouring the mixture into a preheated mold and kept in a vacuum oven for $3 \mathrm{~h}$. The blends were cured at $50{ }^{\circ} \mathrm{C}$ for $2 \mathrm{~h}, 100{ }^{\circ} \mathrm{C}$ for $3 \mathrm{~h}$ and $150{ }^{\circ} \mathrm{C}$ for $3 \mathrm{~h}$ in the oven and then slowly cooled down to room temperature. The absence of bubbles in the cured parallelepiped bars indicated that the solvent was removed.

\subsection{Measurements and Characterization}

UV-vis measurements were carried out to study the optical transparency of cured RBCP modified epoxy blends. The spectra of cured blends ( $4 \mathrm{~mm}$ thickness) were obtained with a SpectraMax M2 in the range between 200 and $800 \mathrm{~nm}$ at $50 \mathrm{~nm}$ per step.

FESEM images were obtained using ULTRA 55 FESEM based on the renowned GEMENI®FESEM column with beam booster (Nano Technology Systems Division, Carl Zeiss NTS GmbH, Germany) with a tungsten gun and applying $5 \mathrm{kV}$ as the accelerating voltage. The fracture samples for morphology observation were prepared after cooling in liquid $\mathrm{N}_{2}$ then coated with gold by vapor deposition before observation. To obtain better resolution, fracture surface of RBCP modified epoxy blends were etched in 
tetrahydrofuran for $30 \mathrm{~min}$, wash with water. The etched surface was observed by FESEM (shown in Fig. S1 of the Supporting information).

TEM images of RBCP modified epoxy blends was obtained by JEOL JEM-1230L microscope by applying an acceleration voltage of $120 \mathrm{kV}$. The ultrathin sections were prepared using LEICA Ultracut ultramicrotome cooled in liquid $\mathrm{N}_{2}$ and collected on a copper grid.

The temperature dependences of the viscoelastic properties (storage modulus: G' and loss tangent: $\tan \delta$ ) of the cured epoxy or cured blends were examined by TA Q800 (TA Instruments). Dimensions of specimens were $35.5 \times 12 \times 1.5 \mathrm{~mm}^{3}$. The analysis were evaluated in torsion mode, a fixed frequency $1 \mathrm{~Hz}$, amplitude $15 \mu \mathrm{m}$, and run from $-100{ }^{\circ} \mathrm{C}$ to $200{ }^{\circ} \mathrm{C}$ with temperature increases of $5{ }^{\circ} \mathrm{C}$ per minute. The peak in $\tan \delta$ was considered to be the glass-transition temperature $(\mathrm{Tg})$.

Fracture toughness measurements were performed following the linear elastic fracture mechanics (LEFM) approach by single edge notched three-point blending (SEN-3PB) method according to ASTM D 504599. The dimensions of parallelepiped specimens are $60 \times 10 \times 5 \mathrm{~mm}^{3}$. Zwick/Roell Z020 universal material tester was used to perform the tests at a test speed of $10 \mathrm{~mm} / \mathrm{min}\left(23{ }^{\circ} \mathrm{C}\right)$. The cracks were carefully generated first cutting a notch of approximately $4.5 \mathrm{~mm}$ using diamond saw blade then tapping a liquid $\mathrm{N}_{2}$ chilled fresh razor blade. Critical stress intensity factor was calculated by average at least 3 specimens.

The impact strength of cured blends was tested using CE $\Lambda$ ST Resil Impactor apparatus at room temperature $\left(23{ }^{\circ} \mathrm{C}\right)$ according to standard GB/T1843. Notched Izod bars with dimensions $80 \times 10 \times 4 \mathrm{~mm}^{3}$ were impacted by $1 \mathrm{~J}$ hammer. 5 specimens were tested and results averaged. The notches were $2 \mathrm{~mm}$ depth, $45^{\circ}$ angle, and $0.25 \mathrm{~mm}$ notch radius.

Room temperature $\left(23^{\circ} \mathrm{C}\right)$ tensile tests were conducted in accordance with ASTM D638 using a Zwick/Roell Z020 universal material tester. Type IV dumbbell shaped bars were obtained by curing blends in Teflon mould. Three crosshead speeds of $0.1,1.0$, and $10 \mathrm{~mm} / \mathrm{min}$ were used in order to cover a range of different tensile behaviour transitions. Average values and standard deviations of Young's modulus, ultimate tensile strength, and elongation at break were calculated based on 3 specimens per sample.

\section{Results and discussion}

\subsection{Structure and Morphology}

Figure 1 shows the UV-vis transmittance spectra of neat epoxy and all RBCP modified epoxy blends. The transmittance is strongly related with the thickness of samples, in this case was $4 \mathrm{~mm}$. Other studies have reported similar wavelength-transmittance curves for neat epoxy.[41] The transmittance gradually increases as $w_{S M A}$ of incorporated RBCP increases, indicating that RBCP with higher reactivity in epoxy blends had weak effect of light absorption in both visible and UV ranges. The most significant decrease in transmittance was observed in $10 \mathrm{wt} \% \mathrm{R} 2 \mathrm{BCP}$ modified epoxy blends, which had a transmittance lower than $15 \%$ in visible range and zero in UV range. This might be due to the fact that the size of inclusions in epoxy matrix increases from nano level (R15BCP modified) to macro level (R2BCP modified).[33] Further studies were done using FESEM and TEM, and the results confirmed this initial observation. 


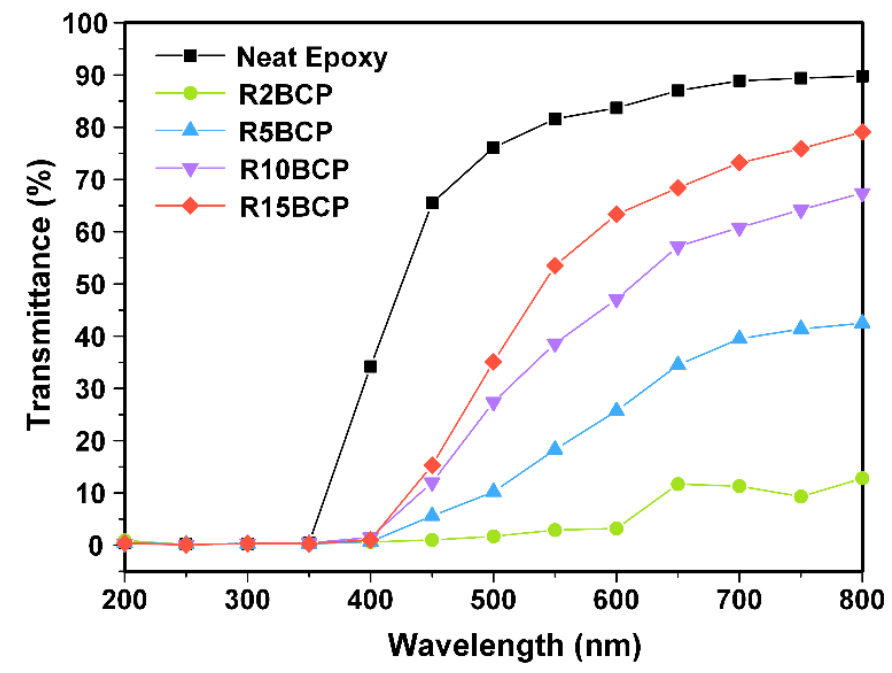

Fig 1. UV-vis transmittance spectra of cured neat epoxy and $10 \mathrm{wt} \% \mathrm{RBCP}$ modified epoxy blends. The RBCP names in figure legend indicate the corresponding modified blends.

TEM photographs of the cured blends in Figure 2 clearly reveal the difference in the size of the internal phase structures. Inclusions in nanometers were found in R5BCP, R10BCP, and R15BCP modified epoxy blends. The blends containing $10 \mathrm{wt} \%$ R5BCP showed nano inclusions $(120 \mathrm{~nm})$, in irregular shape, dispersed in the epoxy resin matrix (Figure 2a). Nanospheres of $80 \mathrm{~nm}$ were observed in $10 \mathrm{wt} \% \mathrm{R} 10 \mathrm{BCP}$ modified epoxy resin (Figure 2b). The cured DGEBA/DDM containing $10 \mathrm{wt} \%$ R15BCP produces micelles, in diameter about $40 \mathrm{~nm}$ (Figure 2c).
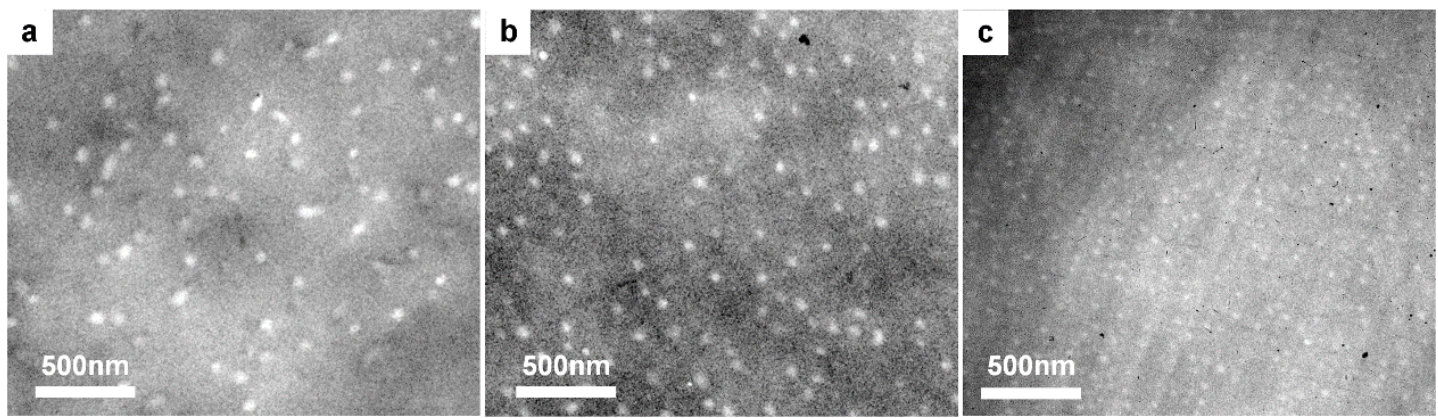

Fig 2. TEM photographs of DGEBA/DDM modified with $10 \mathrm{wt} \%$ of (a) R5BCP, (b) R10BCP, and (c) R15BCP. Scale bars are all $500 \mathrm{~nm}$.

The cryogenic fractured surfaces of neat epoxy, epoxy thermosets modified with R2BCP, R5BCP, and R10BCP were observed via FESEM to reveal the size of inclusions. Figure 3 shows representative images of fractured surfaces containing inclusions from nanometers to micrometers. The neat epoxy reveals a single phase (Figure 3a). The fracture surface is typically smooth, indicating a brittle material. The RBCP modified epoxy blends show rougher surface with respect to neat epoxy. R2BCP modified epoxy blends macrophase separated micro inclusions are observed. For blends modified by R5BCP, nano inclusions in irregular shapes are dispersed on the fracture surface, appear to be on the verge of macroscopic phase separation. For R10BCP modified blends, the inclusions are almost nanospheres. However, the surface profiles of R15BCP modified blends were no obtained because the thickness of gold coating on fracture 
surfaces of R15BCP modified blends is comparable to the size of inclusions. To enhance contrast between phases, the fracture surfaces of epoxy blends modified by R2BCP, R5BCP, and R10BCP were etched.[42, 43] The etched surface were also observed by FESEM (showed in Fig. S1 of the Supporting information). The fracture surfaces of epoxy blends containing R2BCP (Fig. S1a) show large voids. The completely etching suggest the poor interfacial adhesion between R2BCP and epoxy matrix. R5BCP modified blends were partly etched (Fig. S1b), indicating that small fractions of R5BCP were expelled from epoxy matrix. The R10BCP modified blend was almost no etch during this process (Fig. S1c), this could be due to the strong interfacial adhesion between R10BCP and epoxy matrix. By comparing micrographs of fractured surface before and after etching, we found the completely etching of R2BCP, the partly etching of $\mathrm{R} 5 \mathrm{BCP}$, and almost no etch of R10BCP in epoxy matrix. Since the reactive block copolymer is possibly link to DGEBA, we cannot exclude the existence of epoxy phase in self-assembled RBCP showing lamellar morphology in inclusion. However, by analysing the volume fraction of RBCP and electron microscope images, the epoxy phase inside RBCP inclusions can be neglected. Therefore, the R2BCP and $\mathrm{R} 5 \mathrm{BCP}$ inclusions are mainly tetrablock copolymers.
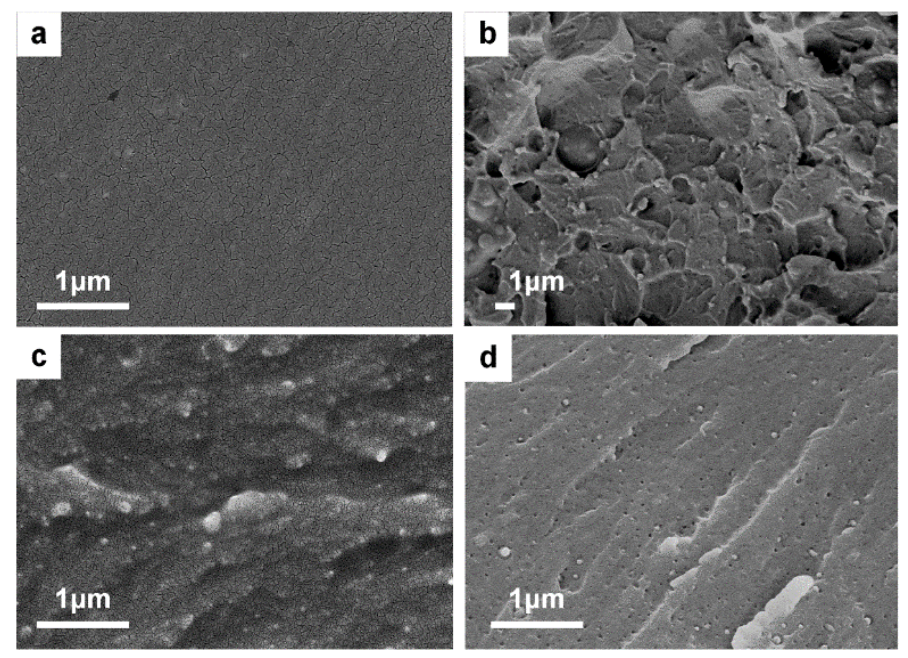

Fig 3. FESEM photographs of fractured surfaces of cured DGEBA/DDM epoxy containing (a) 0 wt $\%$ RBCP, (b) 10 wt \% R2BCP, (c) $10 \mathrm{wt} \%$ R5BCP, and (d) $10 \mathrm{wt} \%$ R10BCP. Scale bar are all $1 \mu \mathrm{m}$, note that the magnification of (b) is five times smaller than others.

A BCP in epoxy resin may self-assemble and form well-defined micro/nanostructures. The type of structure formed depends on the molecular weight, block length, composition, block-block/block-matrix interaction parameters, cosolvent addition, and annealing time.[44-46] Two competitive strategies of CABA tetrablock copolymer self-assembly are proposed and illustrated in Scheme 2a. One is at the surface and subsurface of RBCP inclusions in the epoxy matrix. The tetrablock copolymer is considered as quasi diblock copolymer (C-ABA), composed of maleic-anhydride alternating structure which is epoxy-reactive and hard-soft-hard traditional elastomeric copolymer block sequence which is epoxyimmiscible. The covalent bond formed between SMA block and epoxy matrix is a key factor governing the epoxy-RBCP miscibility. The interfacial curvature could be determined by the geometrical constraints of the block copolymers to balance the competing factors, such as achieving a constant density of the polymer chain and minimizing the chain stretching. [47] The other strategy is inside inclusion, forming lamellar structure composed of RBCPs which is expelled from epoxy matrix. The tetrablock copolymer is considered as quasi triblock copolymer (CA-B-A) and self-assemble to form lamellar morphology. In this 
way, the competition of these two strategies is controlled by modifying the reactivity of RBCP. Then the size of inclusions are determined.

As $w_{S M A}$ increases, the RBCP domain size decreases, smoother surface were observed, indicating the morphological change from heterogeneous to homogeneous. With increasing $w_{S M A}$ of RBCP, more carboxyl groups in SMA block are available to interact with epoxy network, giving stronger interfacial adhesion to the epoxy network. It is hence a phase structure with a smaller size exists in epoxy blends containing RBCP with a higher $w_{S M A}$. Based on the analysis of microscopy observation, an illustrative cartoon of the morphology is illustrated in Scheme 2b. In Scheme 2b, we name the morphologies of $\mathrm{R} 2 \mathrm{BCP}$ and R5BCP modified blends as co-continuous because the coexistence of continuous phase of block copolymer and continuous phase of epoxy resin. The inclusion size is predictable which decrease with the increasing miscibility/reactivity of RBCP. Smaller RBCP domains can be obtained by systematically increase $w_{S M A}$ in RBCP in composites. SMA block of the RBCPs is reactive with epoxy. The phase sizes of the polymer blends can be controlled in the order of either nano meters or micrometers. Different from diblock copolymers, the multiblock copolymers have been observed to form co-continuous morphologies.[48] In addition, aggregated block ionomer spherical micro-domains were also observed.[49]

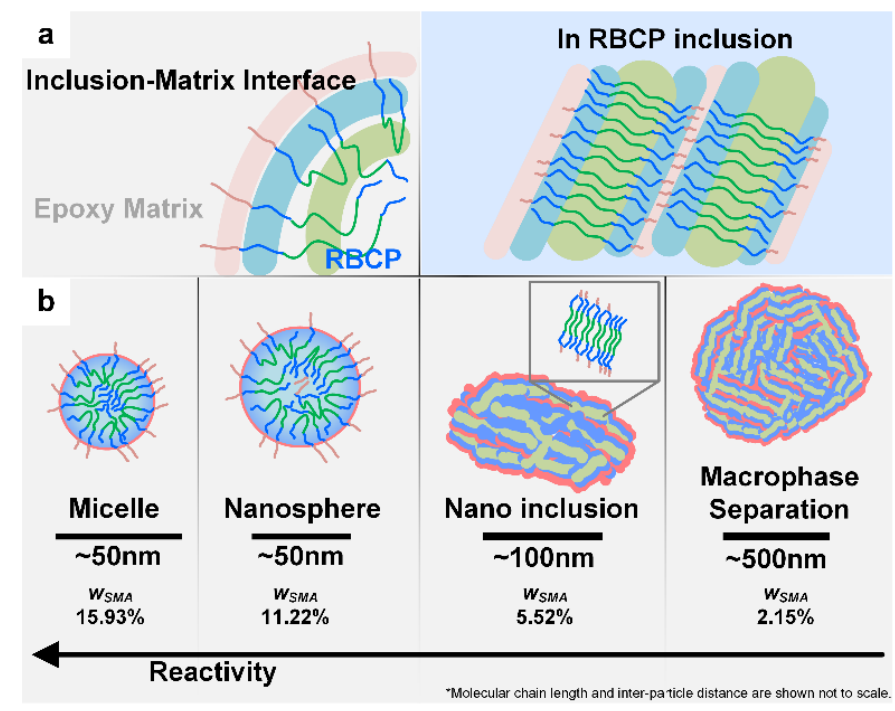

Scheme 2. Morphological scheme of (a) two self-assemble behaviours SMA-PSt-PnBA-PSt in epoxy blends. (b) R2BCP, R5BCP, R10BCP, and R15BCP modified epoxy blends, illustrating the RBCP inclusion from nano-sized micelle to macrophase separation.

\subsection{Thermal Behaviour}

The glass transition temperature $\left(T_{g}\right)$ of the cured composite resins were characterized in DMA measurements. The storage modulus and $\tan \delta$ values of cured epoxy blends plotted against temperature are presented in Figure 4. The main peak in tan $\delta$ curve, corresponds to $\alpha$ transition, is associated as glass transition temperature of epoxy blends. The relaxation at around $-60{ }^{\circ} \mathrm{C}$, denoted as $\beta$-relaxation, is attributed to the motion of the hydroxyl ether structural units and other parts in the polymer chains. The neat epoxy was observed to have a thermal transition temperature of $142{ }^{\circ} \mathrm{C}$ by DMA measurement. Significant decrease in $T_{g}$ was observed for R2BCP modified blends. In macrophase separated blends 
containing R2BCP, the epoxy matrix was effectively plasticized by phase segregated block copolymer and exhibited a lower $T_{g}$ value than the neat epoxy. Slight increase in $T_{g} \mathrm{~s}$ was observed for microphase separated blends, modified by R5BC, R10BCP, and R15BCP. This may be mainly due to the covalent links formed between reactive SMA block and DGEBA, leading to higher degrees of crosslinking. The increased $T_{g}$ were also reported for blends containing nano inclusions. [50] This is in accordance with morphologies from TEM and FESEM observations.
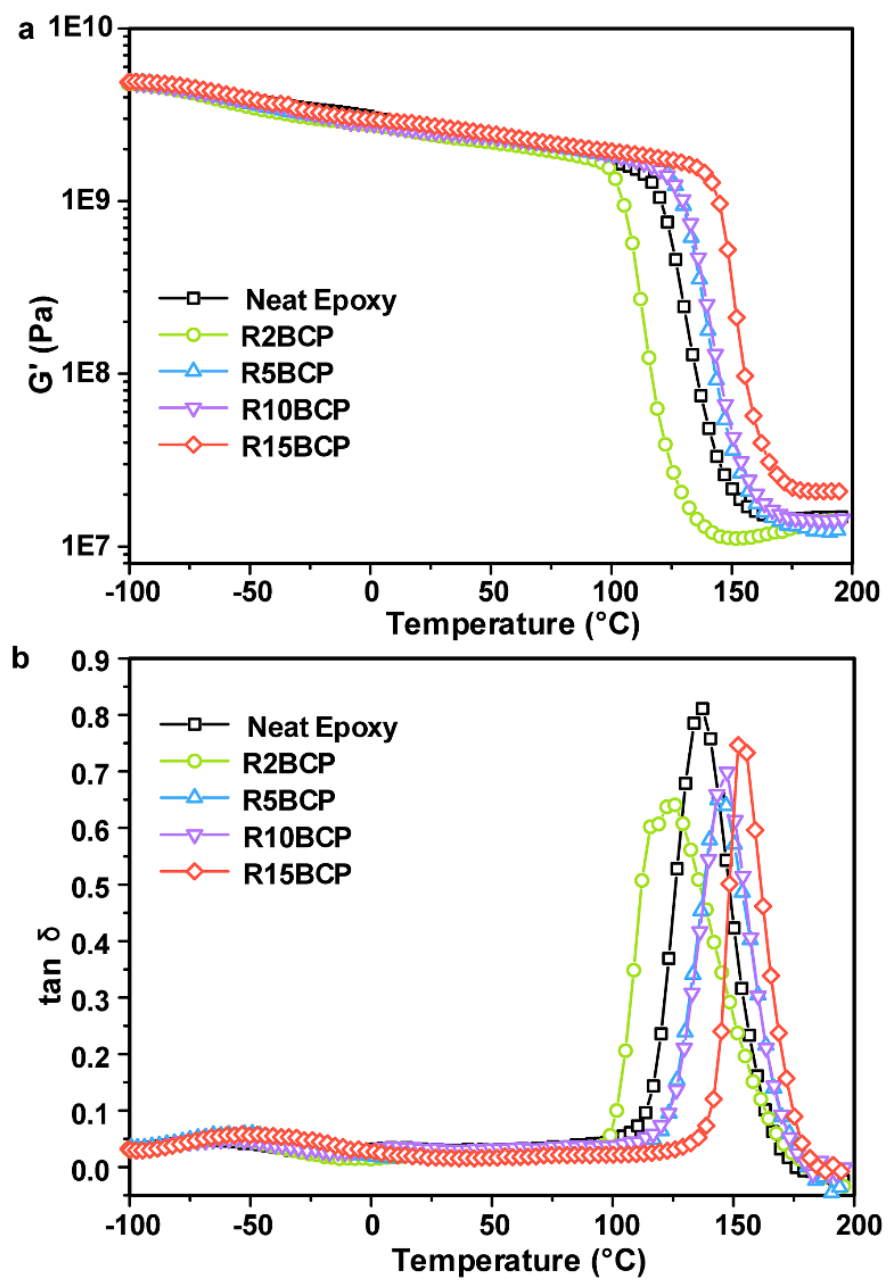

Fig 4. DMA plots of neat epoxy and epoxy blends modified with R2BCP, R5BCP, R10BCP, and R15BCP. (a) Storage Modulus ( $\mathrm{G}^{\prime}$ ) as a function of temperature and (b) $\tan \delta$ curves as a function of temperature is presented. The RBCP names in figure legend indicate the corresponding modified blends.

\subsection{Fracture Properties}

Typical unfilled epoxy resins possess plane strain fracture toughness values near $0.83 \mathrm{MPa} \cdot \mathrm{m}^{1 / 2}$. The morphology of the blends, modifier nature, and interfacial adhesion between the phases represent determinant factors in the variation of the fracture toughness.[44, 46] The $\mathrm{K}_{\mathrm{IC}}$ values of cured epoxy blends modified with SMA-PSt-PnBA-PSt tetrablock copolymer are compared in Figure 5. The highest fracture toughness value, up to $2.0 \mathrm{MPa} \cdot \mathrm{m}^{1 / 2}$, was obtained with R15BCP modified epoxy blends. The fracture toughness values increase as $w_{S M A}$ of RBCP increases, for more acid groups are available to make 
covalent links to epoxy matrix. The adhesion between reactive block copolymer and epoxy is therefore enhanced, leading to improvement of toughness. Compared to Rebizant et. al., who improved $\mathrm{K}_{\mathrm{IC}}$ of DGEBA/DDM epoxy thermosets by $15 \%$ using SB(MA)) block copolymers incorporating acid-reactive functionalities in the last block as modifiers, the advantage of RBCP used in this study is the highly concentrated reactive groups. [39] The $140 \%$ increase in $\mathrm{K}_{\mathrm{IC}}$ of $\mathrm{R} 15 \mathrm{BCP}$ modified blends was attributed to higher interfacial adhesion and highly ordered micelle morphology than previous studies.

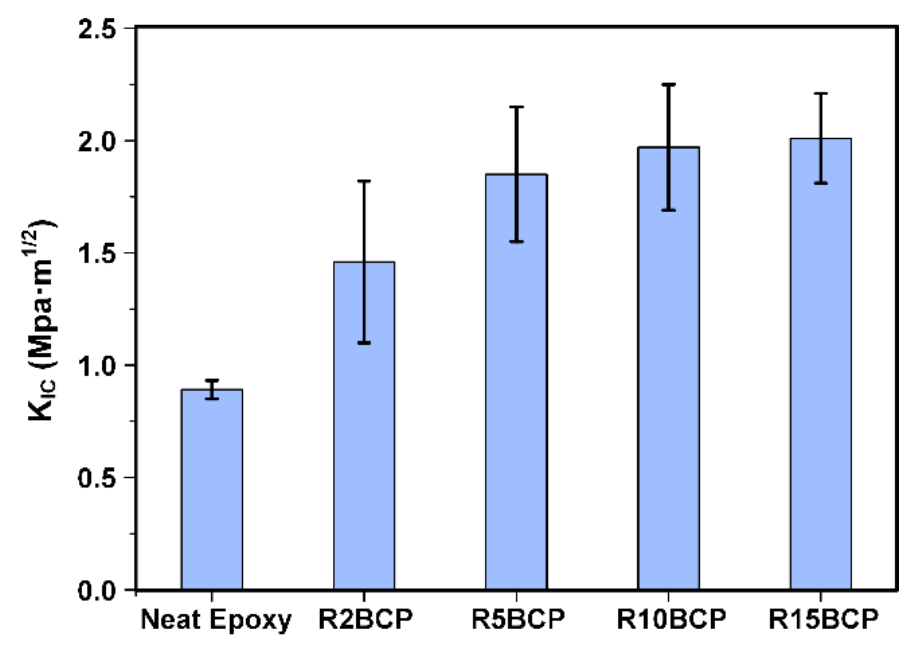

Fig 5. Fracture toughness values of DGEBA/DDM thermosets modified by $10 \mathrm{wt} \%$ of RBCP. The RBCP names in figure legend indicate the corresponding modified blends.

FESEM micrographs (Figure 6) of the SENB fracture surface just beyond the starter crack for (a) R2BCP modified epoxy blend and (b) R10BCP modified epoxy blend show the effects of interfacial adhesion on inclusion-matrix debonding. For R2BCP modified blends, smooth voids can be found on the crack surface. Some R2BCP inclusions still stayed in the holes, with diameter smaller than the voids. This indicates that the particle itself may possibly undergo no plastic deformation due to interfacial debonding. So that there were limited matrix dilatation or deformation surrounding the voids. For R10BCP modified blends, inclusions produce fibrillary structures during interfacial debonding. This would like to induce cavitation or deformation of R10BCP inclusion. Thus, the fracture toughness of epoxy blends modified by $\mathrm{R} 10 \mathrm{BCP}$ is increased compared to blends modified by R2BCP at same loading. These drawn fibrillary structures also were seen in reactive vesicles in various sizes and appear to be a typical feature of the particle-matrix interface for reactive vesicles.[46] It is not clear from the FESEM micrographs whether the fibrils are composed of epoxy external to RBCP inclusion or how the bilayer is deformed during debonding. 


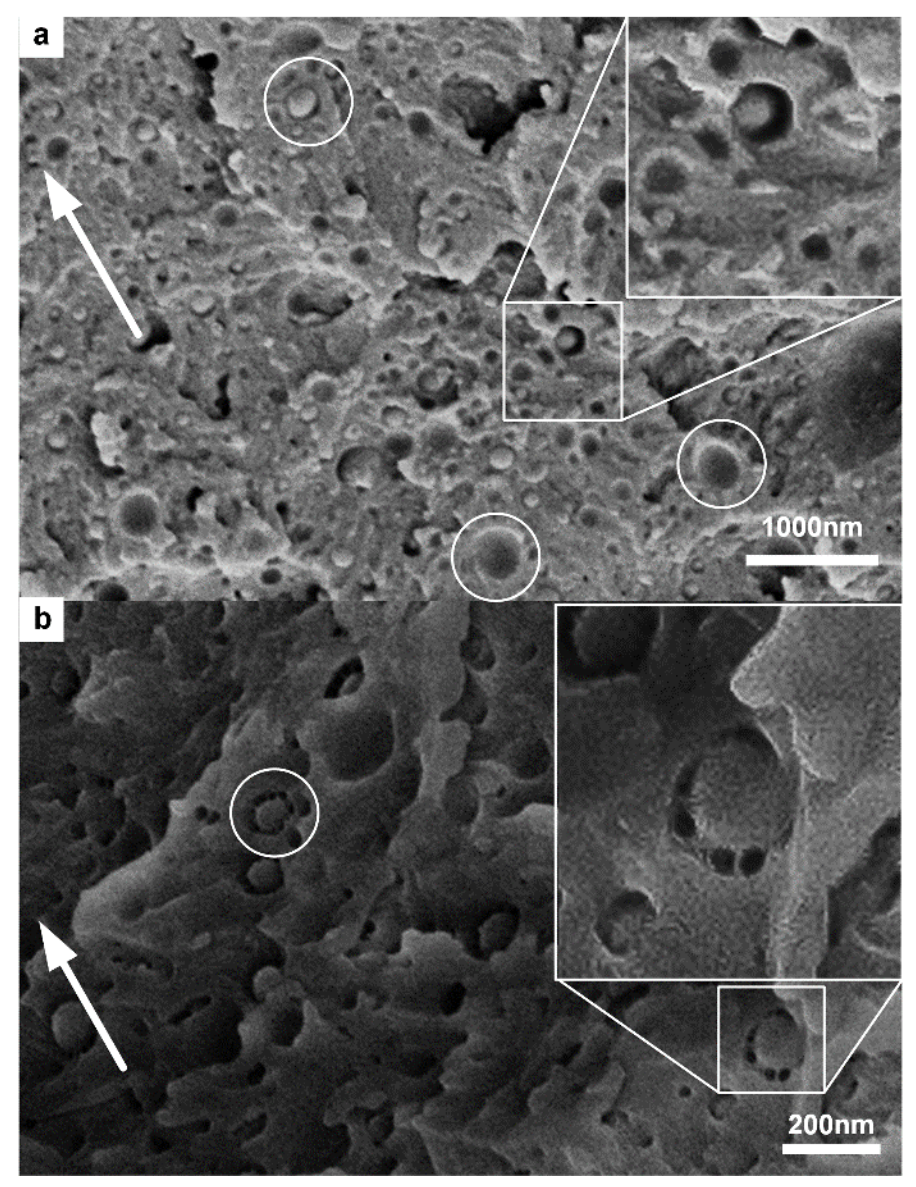

Fig 6. FESEM micrographs of the SENB fracture surface just beyond the starter crack for (a) R2BCP modified epoxy blend and (b) R10BCP modified epoxy blend. The arrows indicate the direction of crack propagation. The inset shows the magnified particle The R2BCP particles debond cleanly from the epoxy matrix, when the R10BCP particles form fibrils during debonding.

Figure 7 shows the impact strength of the different weight fractions of RBCP modified DGEBA/DDM blends, significant increase in notched impact strength of RBCP modified blends is achieved with respect to the neat epoxy resin. The highest impact strength was obtained with R5BCP modified DGEBA/DDM blends, rather than R10BCP and R15BCP modified blends. The strain-rate dependence on morphologies and RBCP viscoelastic nature may be the reason. Here we note that the conclusions may be systemdependent, because block copolymer nature in this study is the key factor achieving various morphologies.[51] Blends containing smaller inclusions of RBCP seem to be more sensitive to test rates, which will be discussed later. 


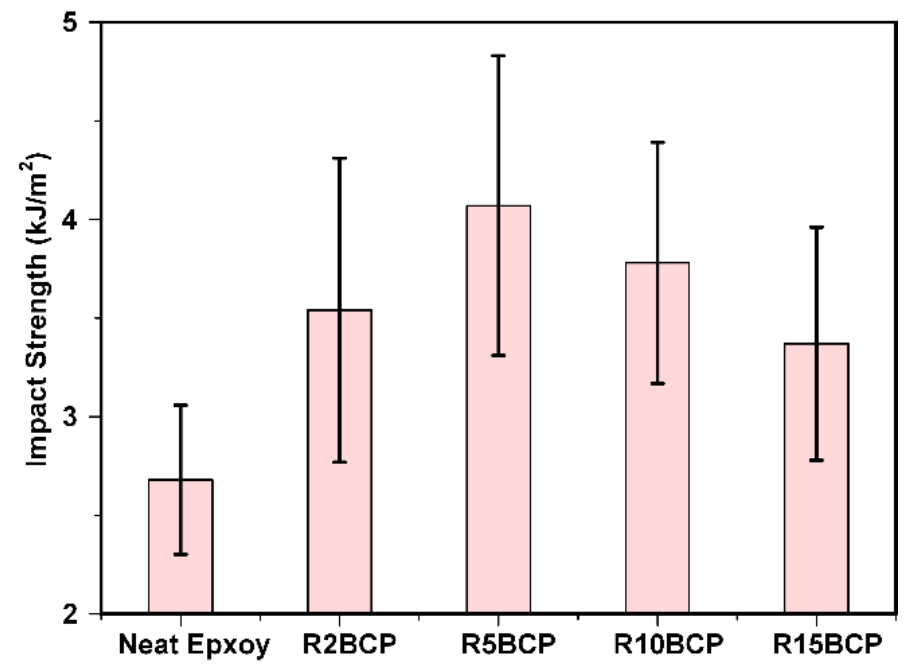

Fig 7. Notched IZOD impact strength of DGEBA/DDM thermosets modified by $10 \mathrm{wt} \%$ of RBCP. The RBCP names in figure legend indicate the corresponding modified blends.

The mechanical properties of epoxy blends in this study are presented in Table 2 . The elastic modulus $E$ of R2BCP modified blends is significantly lower than microphase separated blends. The low-modulus inclusions are able to reduce the plastic resistance of the epoxy matrix. Similar trends have also been described elsewhere.[52] The $G_{I C}$ value of neat epoxy in this study is $212.4 \mathrm{~J} / \mathrm{m}^{2}$. The highest $G_{I C}$ was obtained by R15BCP modified blends, which is $1371 \mathrm{~J} / \mathrm{m}^{2}, 6.5$ times the value of unmodified ones. The strain energy release rate of R5BCP modified epoxy is 6 times the value of neat epoxy.

Table 2. $K_{I C}$, E, $G_{I C}$, Impact strength $(I)$, and $T_{g}$ of RBCP modified epoxy blends in this study. The RBCP names in figure legend indicate the corresponding modified blends.

\begin{tabular}{cccccc}
\hline Sample & $\mathrm{K}_{\mathrm{IC}}\left(\mathrm{MPa} \mathrm{m}^{1 / 2}\right)^{\mathrm{a}}$ & $\mathrm{E}(\mathrm{GPa})^{\mathrm{b}}$ & $\mathrm{G}_{\mathrm{IC}}\left(\mathrm{J} / \mathrm{m}^{2}\right)^{\mathrm{c}}$ & $\mathrm{I}\left(\mathrm{kJ} / \mathrm{m}^{2}\right)^{\mathrm{d}}$ & $\mathrm{T}_{\mathrm{g}}\left({ }^{\circ} \mathrm{C}\right)^{\mathrm{e}}$ \\
\hline Neat Epoxy & 0.83 & 2.89 & 212.4 & 2.68 & 142.35 \\
R2BCP & 1.46 & 2.41 & 782.2 & 3.54 & 121.18 \\
R5BCP & 1.85 & 2.47 & 1225 & 4.07 & 144.94 \\
R10BCP & 1.97 & 2.53 & 1357 & 3.78 & 145.85 \\
R15BCP & 2.05 & 2.71 & 1371 & 3.37 & 153.23 \\
\hline
\end{tabular}

${ }^{a}$ Stress intensity factor $\left(\mathrm{K}_{\mathrm{IC}}\right)$ was obtained from SENB tests on at least 3 specimens. ${ }^{\mathrm{b}}$ Elastic modulus were obtained from DMA measurements. ${ }^{c}$ Strain energy release rate $\left(\mathrm{G}_{\mathrm{IC}}\right)$ calculated from $\mathrm{K}_{\mathrm{IC}}$ and $\mathrm{E}$ using equation: $\mathrm{G}_{\mathrm{IC}}=\mathrm{K}_{\mathrm{IC}}{ }^{2}\left(1-v^{2}\right) / \mathrm{E}$, and Possion's Ratio $v=0.34$. ${ }^{\mathrm{d}}$ Impact strength was obtained according to GB/T 1843 on at least 5 specimens. ${ }^{\mathrm{e}} \mathrm{T}_{\mathrm{g}} \mathrm{s}$ were obtained from DMA analysis.

\section{Tensile Properties}

To investigate the difference toughness value reported in SENB tests and notched IZOD impact strength, tensile tests were performed on neat epoxy, R5BCP modified blends, and R15BCP modified blends. The room temperature tensile tests were conducted at a test speed of $1.0,10.0$, and $100.0 \mathrm{~mm} / \mathrm{min}$. The stressstrain curves are displayed in Figure 8 and the key tensile properties are summarized (Showed in Table. $\mathrm{S} 1$ of the Supporting information). As the tensile speed increased, the elastic modulus increased and the elongation at break decreased. This implies that it is harder to undergo plastic deformation as the test rate 
increased. For neat epoxy and R5BCP modified epoxy blends, there was no decrease in ultimate tensile strength as test speed increased. However, ultimate tensile strength of R15BCP modified blends decreased in a higher tensile rate. The tensile properties of these blends strongly related to the test rate. Spherical micelles of block copolymer modified epoxy blends were more strain rate sensitive than neat epoxy.[53] In a toughened polymeric system, the micromechanical deformation mechanism for fracture behaviour involves a time-dependent process, which is related to the relaxation of the matrix molecules with respect to the applied strain rate of the test. At high test rates, the volumetric dilatation of the RBCP inclusion remained too low when early brittle failure occurred in the matrix. The tensile test indicates that R15BCP modified epoxy blends in notched IZOD impact tests may possibly undergo mainly matrix deformation rather than inclusion rubber cavitation where the matrix is really brittle.
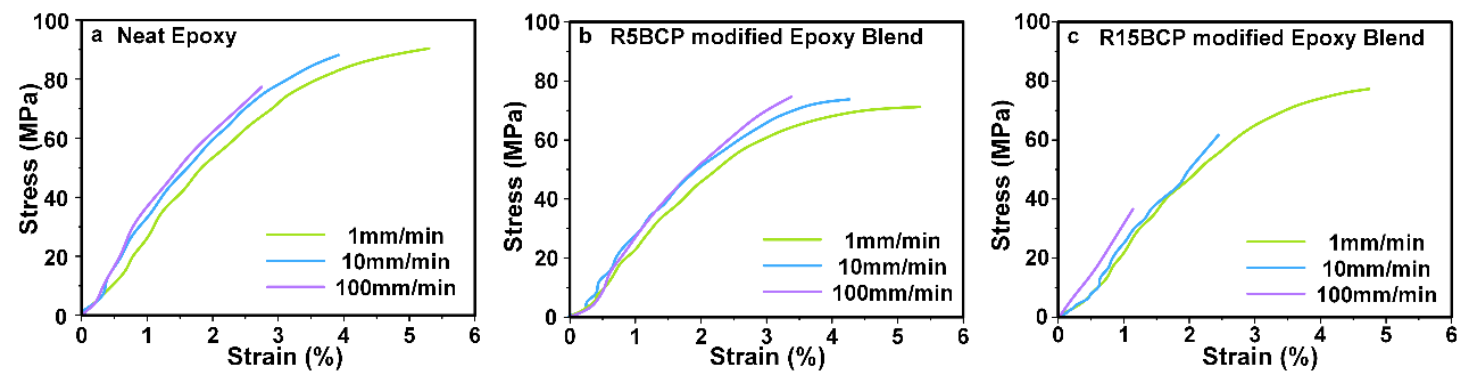

Fig 8. Stress-strain curve of reactive block copolymer modified epoxy blends, (a) Neat Epoxy; (b) R5BCP modified blends; (c) R15BCP modified blends.

The inclusion size may play different roles in low speed fracture scheme, i.e. SENB test, or high speed fracture scheme, i.e. impact tests. The temperature-time effects in the notched fracture behaviour of polymer composites may be the reason.[54-56] R10BCP or R15BCP was likely to form more covalent bond with epoxy than R5BCP, which decreased the ductility of the matrix. Therefore, epoxy blends modified by smaller inclusions are more sensitive to immediate deformation, namely, high speed fracture tests. In this study, R10BCP and R15BCP modified DGEBA/DDM blends produced smaller inclusion than R5BCP and R2BCP modified ones. The sub-micron and co-continuous inclusions of RBCP modified epoxy blends were more effective in impact tests than nano-sized micelle inclusions. The similar cocontinuous morphologies were found to be highly effective in notched impact tests for some other polymer composites such as super-tough polyamides.[48] However, there was no clear evidence could tell whether the inclusions size or the co-continuous nanostructure matters. Considering R5BCP modified blends, having irregular sub-micron inclusions, show good toughening effect both at low and high test speeds and a stronger tendency of self-assembly in R2BCP inclusions, we suggest it is inclusion size rather than the co-continuous nanostructure which correlates to toughness of these blends. Although we correlated inclusion size to mechanical properties, the compatibility between RBCP and matrix, i.e. reactivity of RBCP, determined inclusion size and nanostructures at same loading.

On the other hand, it must be noticed that the reactive block copolymer employed in this study display various viscoelastic nature as we previously reported.[40] The bulk RBCP with increased $w_{S M A}$ show higher stiffness and lower ductility. Compared with R10BCP modified blends, the R2BCP modified ones are estimated to be modified by inclusions containing more rubber content. A decrease in $T_{g}$ was observed in blends with macrophase separation and complex inclusions, giving rise to a more rubbery matrix. Inclusions with higher rubber content were easier to cavitate in high speed tests. Care must be taken when 
toughened polymers are to be utilized for high fracture rate applications. The detail of the toughening mechanisms on different morphologies will be discussed in future studies.

\section{Conclusions}

The experimental results presented in the previous sections established the effective modification of DGEBA/DDM epoxy resin by SMA-PSt-PnBA-PSt reactive tetrablock copolymers. By simply changing the reactivity of RBCP, the inclusion size can be tailored over a broad range of length scales from nano meters to micro meters. The inclusions in blends were formed via two main competitive strategies. One is self-assembly of C-ABA quasi-diblock copolymer in epoxy matrix, where the epoxy matrix was used as selective solvents of the RBCP. The other is self-assembly of CA-B-A quasi-triblock copolymer inside RBCP inclusions. The fracture toughness value $\left(\mathrm{K}_{\mathrm{IC}}\right)$ of R15BCP modified DGEBA/DDM systems was 2.0 $\mathrm{MPa} \cdot \mathrm{m}^{1 / 2}$, which was a significant toughness improvement for block copolymer modified DGEBA/DDM epoxy thermosets. However, the highest impact strength (50\% increase with respect to neat epoxy) was measured for R5BCP modified epoxy blends.

The toughness measurements suggest the difference between in high speed fracture scheme such as IZOD impact tests and low speed fracture scheme such as fracture toughness test. The results indicate the different strain rate dependence on inclusion size of RBCP modified epoxy composites, where nano inclusions were found to be sensitive to test rates. And sub-micron inclusions showed good toughening effect both at low and high test speeds. The findings of this work provide an efficient strategy for developing high-performance thermosets via an innovative reactive blending, where miscibility block is replaced by a much shorter reactive block.

\section{Acknowledgements}

The authors would like to thank the National Science Foundation of China (NSFC) for Award No. 21276224, 21476195, 21576236 and Zhejiang Provincial National Science Foundation of China Y14B060038 for supporting this research.

Appendix A. Supplementary data

Supplementary data related to this article can be found at http://dx.doi.org/10.1016/j.polymer.

\section{References}

[1] Jones AR, Watkins CA, White SR, Sottos NR. Self-healing thermoplastic-toughened epoxy. Polymer 2015;74:254-261.

[2] Everitt DT, Luterbacher R, Coope TS, Trask RS, Wass DF, Bond IP. Optimisation of epoxy blends for use in extrinsic self-healing fibre-reinforced composites. Polymer 2015;69:283-292.

[3] Downey MA, Drzal LT. Toughening of aromatic epoxy via aliphatic epoxy copolymers. Polymer 2014;55:6658-6663.

[4] Wang M, Fan X, Thitsartarn W, He C. Rheological and mechanical properties of epoxy/clay nanocomposites with enhanced tensile and fracture toughnesses. Polymer 2015;58:43-52.

[5] Kinloch AJ, Lee SH, Taylor AC. Improving the fracture toughness and the cyclic-fatigue resistance of epoxy-polymer blends. Polymer 2014;55:6325-6334.

[6] Cicala G, La Spina R, Recca A, Sturiale S. Influence of copolymer's end groups and molecular weights on the rheological and thermomechanical properties of blends of novel thermoplastic copolymers and epoxy resins. J Appl Polym Sci 2006;101:250-257. 
[7] Mijovic J, Shen M, Sy JW, Mondragon I. Dynamics and Morphology in Nanostructured Thermoset Network/Block Copolymer Blends during Network Formation. Macromolecules 2000;33:5235-5244.

[8] Fan W, Wang L, Zheng S. Double Reaction-induced Microphase Separation in Epoxy Resin Containing Polystyrene-block-poly(E-caprolactone)-block-poly(n-butyl acrylate) ABC Triblock Copolymer. Macromolecules 2010;43:10600-10611.

[9] Meng Y, Zhang X, Du B, Zhou B, Zhou X, Qi G. Thermosets with core-shell nanodomain by incorporation of core crosslinked star polymer into epoxy resin. Polymer 2011;52:391-399.

[10] Gao J, Li J, Benicewicz BC, Zhao S, Hillborg H, Schadler LS. The Mechanical Properties of Epoxy Composites Filled with Rubbery Copolymer Grafted SiO2. Polymer 2012;4:187-210.

[11] Chen J, Kinloch AJ, Sprenger S, Taylor AC. The mechanical properties and toughening mechanisms of an epoxy polymer modified with polysiloxane-based core-shell particles. Polymer 2013;54:4276-4289.

[12] Gao J, Li J, Zhao S, Benicewicz BC, Hillborg H, Schadler LS. Effect of graft density and molecular weight on mechanical properties of rubbery block copolymer grafted $\mathrm{SiO} 2$ nanoparticle toughened epoxy. Polymer 2013;54:3961-3973.

[13] Yang B, Wang W, Huang J. Synergic effects of poly(vinyl butyral) on toughening epoxies by nanostructured rubbers. Polymer 2015;77:129-142.

[14] Malakooti MH, Anderson PL, Sodano HA. Toughening mechanism of heterogeneous aliphatic polyurethanes. Polymer 2014;55:2086-2093.

[15] Ritzenthaler S, Court F, David L, Girard-Reydet E, Leibler L, Pascault JP. ABC Triblock Copolymers/Epoxy-Diamine Blends. 1. Keys To Achieve Nanostructured Thermosets. Macromolecules 2002;35:6245-6254.

[16] Lipic PM, Bates FS, Hillmyer MA. Nanostructured Thermosets from Self-Assembled Amphiphilic Block Copolymer/Epoxy Resin Mixtures. J Am Chem Soc 1998;120:8963-8970.

[17] Meng F, Zheng S, Li H, Liang Q, Liu T. Formation of Ordered Nanostructures in Epoxy Thermosets: A Mechanism of Reaction-Induced Microphase Separation. Macromolecules 2006;39:50725080 .

[18] Liu JD, Thompson ZJ, Sue H, Bates FS, Hillmyer MA, Dettloff M, Jacob G, Verghese N, Pham H. Toughening of Epoxies with Block Copolymer Micelles of Wormlike Morphology. Macromolecules 2010;43:7238-7243.

[19] Kishi H, Kunimitsu Y, Imade J, Oshita S, Morishita Y, Asada M. Nano-phase structures and mechanical properties of epoxy/acryl triblock copolymer alloys. Polymer 2011;52:760-768.

[20] Wu S, Peng S, Hameed N, Guo Q, Mai Y. A new route to nanostructured thermosets with block ionomer complexes. Soft Matter 2011;8:688-698.

[21] Garate H, Goyanes S, D Accorso NB. Controlling Nanodomain Morphology of Epoxy Thermosets Modified with Reactive Amine-Containing Epoxidized Poly(styrene-b-isoprene-b-styrene) Block Copolymer. Macromolecules 2014;47:7416-7423.

[22] Hillmyer MA, Lipic PM, Hajduk DA, Almdal K, Bates FS. Self-assembly and polymerization of epoxy resin-amphiphilic block copolymer nanocomposites. J Am Chem Soc 1997;119:2749-2750.

[23] Cong H, Li L, Zheng S. Formation of nanostructures in thermosets containing block copolymers: From self-assembly to reaction-induced microphase separation mechanism. Polymer 2014;55:1190-1201.

[24] Cong H, Li L, Zheng S. Cylindrical brush copolymer bearing polystyrene-block-poly( $\varepsilon$-caprolactone) diblock side chains: Synthesis via a sequential grafting-from polymerization approach and its formation of fibrillar nanophases in epoxy thermosets. Polymer 2015;79:99-109.

[25] Li J, Cong H, Li L, Zheng S. Nanostructured thermosets containing $\pi$-conjugated polymer nanophases: Morphology, dielectric and thermal conductive properties. Polymer 2015;69:193-203.

[26] Zucchi IA, Schroeder WF. Nanoribbons with semicrystalline core dispersed in a visible-light photopolymerized epoxy network. Polymer 2015;56:300-308.

[27] Paul DR, Robeson LM. Polymer nanotechnology: Nanocomposites. Polymer 2008;49:3187-3204.

[28] Ruiz-Pérez L, Royston GJ, Fairclough JPA, Ryan AJ. Toughening by nanostructure. Polymer 2008;49:4475-4488.

[29] Li X, Kang H, Shen J, Zhang L, Nishi T, Ito K, Zhao C, Coates P. Highly toughened polylactide with 
novel sliding graft copolymer by in situ reactive compatibilization, crosslinking and chain extension. Polymer 2014;55:4313-4323.

[30] Grubbs RB, Dean JM, Broz ME, Bates FS. Reactive Block Copolymers for Modification of Thermosetting Epoxy. Macromolecules 2000;33:9522-9534.

[31] Rebizant V, Abetz V, Tournilhac F, Court F, Leibler L. Reactive Tetrablock Copolymers Containing Glycidyl Methacrylate. Synthesis and Morphology Control in Epoxy-Amine Networks. Macromolecules 2003;36:9889-9896.

[32] Yi F, Yu R, Zheng S, Li X. Nanostructured thermosets from epoxy and poly(2,2,2-trifluoroethyl acrylate)-block-poly(glycidyl methacrylate) diblock copolymer: Demixing of reactive blocks and thermomechanical properties. Polymer 2011;52:5669-5680.

[33] George SM, Puglia D, Kenny JM, Causin V, Parameswaranpillai J, Thomas S. Morphological and Mechanical Characterization of Nanostructured Thermosets from Epoxy and Styrene-block-Butadieneblock-Styrene Triblock Copolymer. Ind Eng Chem Res 2013;52:9121-9129.

[34] Serrano E, Tercjak A, Kortaberria G, Pomposo JA, Mecerreyes D, Zafeiropoulos NE, Stamm M, Mondragon I. Nanostructured Thermosetting Systems by Modification with Epoxidized Styrene-Butadiene Star Block Copolymers. Effect of Epoxidation Degree. Macromolecules 2006;39:2254-2261.

[35] George SM, Puglia D, Kenny JM, Parameswaranpillai J, Thomas S. Reaction-Induced Phase Separation and Thermomechanical Properties in Epoxidized Styrene-block-butadiene-block-styrene Triblock Copolymer Modified Epoxy/DDM System. Ind Eng Chem Res 2014;53:6941-6950.

[36] Jagtap SB, Rao VS, Barman S, Ratna D. Nanocomposites based on epoxy resin and organoclay functionalized with a reactive modifier having structural similarity with the curing agent. Polymer 2015;63:41-51.

[37] Yilmaz S, Gul O, Yilmaz T. Effect of chain extender and terpolymers on tensile and fracture properties of polyamide 6. Polymer 2015;65:63-71.

[38] Liang G, Meng J, Zhao L. Synthesis of styrene-maleic anhydride random copolymer and its compatibilization to poly(2,6-dimethyl-1,4-phenylene ether)/brominated epoxy resin. Polym Int 2003;52:966-972.

[39] Rebizant V, Venet A, Tournilhac F, Girard-Reydet E, Navarro C, Pascault J, Leibler L. Chemistry and Mechanical Properties of Epoxy-Based Thermosets Reinforced by Reactive and Nonreactive SBMX Block Copolymers. Macromolecules 2004;37:8017-8027.

[40] Zhan X, He R, Zhang Q, Chen F. Microstructure and mechanical properties of amphiphilic tetrablock copolymer elastomers via RAFT miniemulsion polymerization: influence of poly[styrene-alt-(maleic anhydride)] segments. RSC Adv 2014;4:51201-51207.

[41] Cano L, Builes DH, Tercjak A. Morphological and mechanical study of nanostructured epoxy systems modified with amphiphilic poly(ethylene oxide-b-propylene oxide-b-ethylene oxide)triblock copolymer. Polymer 2014;55:738-745.

[42] Cicala G, Recca G. Thermomechanical and morphological properties of epoxy blends with hyperbranched polyester: Effect of the pseudo-generation number. J Appl Polym Sci 2010;115:1395-1406. [43] Kishi H, Tanaka S, Nakashima Y, Saruwatari T. Self-assembled three-dimensional structure of epoxy/polyethersulphone/silver adhesives with electrical conductivity. Polymer 2016;82:93-99.

[44] Wu J, Thio YS, Bates FS. Structure and properties of PBO-PEO diblock copolymer modified epoxy. J Polym Sci Polm Phys 2005;43:1950-1965.

[45] Cong H, Li L, Zheng S. Formation of nanophases in epoxy thermosets containing ABC and ACB triblock copolymers: A comparative investigation. Polymer 2015;80:146-158.

[46] Dean JM, Grubbs RB, Saad W, Cook RF, Bates FS. Mechanical properties of block copolymer vesicle and micelle modified epoxies. J Polym Sci Polm Phys 2003;41:2444-2456.

[47] Kishi H, Kunimitsu Y, Nakashima Y, Abe T, Imade J, Oshita S, Morishita Y, Asada M. Control of nanostructures generated in epoxy matrices blended with PMMA-b-PnBA-b-PMMA triblock copolymers. Express. Polym. Lett. 2015;9:23-35.

[48] Corté L, Rebizant V, Hochstetter G, Tournilhac F, Leibler L. Toughening with Little Stiffness Loss: 
Polyamide Filled with ABC Triblock Copolymers. Macromolecules 2006;39:9365-9374.

[49] Wu S, Peng S, Hameed N, Guo Q, Mai Y. A new route to nanostructured thermosets with block ionomer complexes. Soft Matter 2012;8:688-698.

[50] Quan D, Ivankovic A. Effect of core-shell rubber (CSR) nano-particles on mechanical properties and fracture toughness of an epoxy polymer. Polymer 2015;66:16-28.

[51] Redline EM, Declet-Perez C, Bates FS, Francis LF. Effect of block copolymer concentration and core composition on toughening epoxies. Polymer 2014;55:4172-4181.

[52] Wu S, Guo Q, Kraska M, Stühn B, Mai Y. Toughening Epoxy Thermosets with Block Ionomers: The Role of Phase Domain Size. Macromolecules 2013;46:8190-8202.

[53] Liu JD, Sue H, Thompson ZJ, Bates FS, Dettloff M, Jacob G, Verghese N, Pham H. Strain rate effect on toughening of nano-sized PEP-PEO block copolymer modified epoxy. Acta Mater 2009;57:2691-2701. [54] Dijkstra K, Wevers HH, Gaymans RJ. Nylon-6/rubber blends: 7. Temperature-time effects in the impact behaviour of nylon/rubber blends. Polymer 1994;35:323-331.

[55] Manzione LT, Gillham JK, McPherson CA. Rubber-modified epoxies. II. Morphology and mechanical properties. J Appl Polym Sci 1981;26:907-919.

[56] Raghavan D, He J, Hunston D, Hoffman D. Strain rate dependence of fracture in a rubber-toughened epoxy system. The Journal of Adhesion 2002;78:723-739. 


\section{Interfacial}

\section{Lamellar}
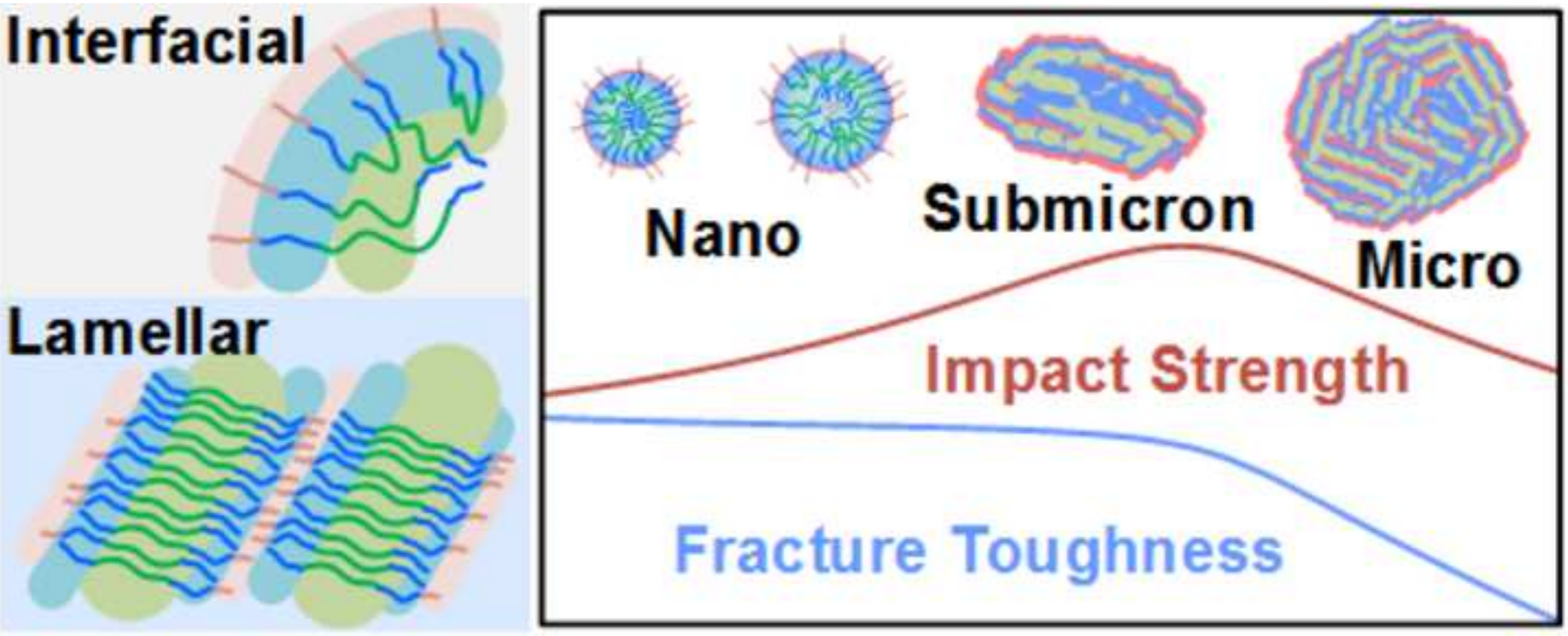